\title{
7. Support for whistleblowing among managers: exploring job satisfaction and awareness of obligations
}

\author{
Paul Mazerolle and A. J. Brown ${ }^{1}$
}

\section{Introduction}

In the remaining chapters of this book, attention turns from whistleblowers and their treatment to the organisational cultures and systems within which whistleblowing occurs and the different elements of how individual organisations currently respond. In understanding organisational responses and some of the possible explanations for the results in Part 1, no issues are more important than those of the roles, knowledge, awareness and attitude of managers.

Among the contradictions in current research on whistleblowing is the dual role that managers often play. On one hand, managers can foster unhealthy work environments that lead to employee complaints, low staff morale and high employee turnover. In an environment in which abusive supervision practices are prevalent, reports of wrongdoing can be expected, especially among employees with moderate levels of organisational commitment (Somers and Casal 1994). In contrast, some managers, for a range of reasons, foster productive and professional work environments that engender more positive experiences among employees. In this context, managers can be expected not only to promote and foster a positive reporting climate, but demonstrate the commitment and capacity to provide more professional and effective responses to whistleblowing. The confidence that effective managers provide to their staff could therefore promote greater employee communication intended to resolve concerns informally or strong assurances that effective responses will be available in the event that formal reports are made.

This duality of roles is well demonstrated in some of the previous chapters. For example, in Chapter 4, we saw that most employees who were prepared to come forward with concerns about wrongdoing were inclined to trust their managers with that information. This predisposition to trust managers is clearly in the organisation's interests. In Chapter 5, however, which focused on outcomes largely from the perspectives of whistleblowers, we saw that managers were likely to be regarded as the source of most bad treatment or harm that whistleblowers experienced. In some cases, the perception that management has failed or deliberately mistreated the whistleblower is unavoidable. Chapter 6 reinforces that especially when managers are implicated in the allegation of 
wrongdoing, the risks of reported whistleblower mistreatment can become very high.

From all of this evidence, there are good reasons to expect that the competence, attitudes and qualities of managers make a material difference in their commitment to the practice of whistleblowing, as well as their support for procedures for handling it. In short, the role of managers within organisational settings is crucial in relation to whether whistleblowing occurs, whether whistleblowing reporting procedures and attitudes to reporting wrongdoing are endorsed or promoted and whether such incidents are managed in a professional and competent manner (Masser and Brown 1996; Vandekerckhove 2006). ${ }^{2}$ While it is often acknowledged that the role of management is crucial in the handling and support of whistleblowing, important questions remain regarding the interaction between organisational experiences and workplace attitudes in determining a manager's level of support for whistleblowing. There has been a limited set of studies linking various organisational characteristics such as workplace culture to whistleblowing (cf. Zhuang et al. 2005), but much of this research has not focused especially on the role of managers. The relationship, therefore, between the workplace attitudes of managers and their attitudes towards whistleblowing is poorly understood.

In this chapter, we examine the relationships between organisational and personal factors and levels of managerial support for whistleblowing. More specifically, we examine whether managers with positive attitudes towards their organisation - as indicated by their job satisfaction, trust in management and organisational citizenship-disproportionately support whistleblowing when compared with other managers and non-managers. The results show job satisfaction to be a salient facilitating factor in managers' support for whistleblowing 'in principle', as well as their reported knowledge of reporting procedures. The findings therefore illustrate how experiences at work, in terms of whether one is satisfied or not, can lead to various tangible benefits across organisations.

We then explore the extent to which managers appear conscious of their specific obligations in respect of the management of whistleblowers, as a continuation of the broader inquiry into how effectively these positive outlooks translate into practice. ${ }^{3}$ These results show that managers are far less certain about rights and obligations relevant to their own role in respect of real whistleblowing incidents. There are also strong signs that managers themselves recognise the need to close the gaps between broad principle and practical realities. While it is clear that managers have a unique role to play in encouraging whistleblowing, the results suggest that a concerted effort is needed if the potential contribution of good management cultures and styles to the productive management of whistleblowing is to be maximised. The major question becomes, how can agency systems and 
procedures build on the general support for whistleblowing that has been found among individual managers? By investing in the job satisfaction of managers as well as by promoting greater awareness among managers of their whistleblowing reporting obligations and procedures, organisations can do a great deal to reduce the risks of some of the outcomes described in earlier chapters and increase the prospects of the whistleblowing process being handled well.

\section{Research focus and method}

Support for whistleblowing generally, as well as knowledge of and support for specific procedures involved in managing whistleblowing, are arguably a reflection of a more professionalised management culture within an organisational setting. In these circumstances, a much lower prevalence of abusive management practices could be expected (Zellars et al. 2002). Our specific concerns in the current chapter involve exploring relationships between managers and non-managers across public sector organisations on various organisational climate indicators, as well as their attitudes and commitment towards whistleblowing generally and knowledge of procedures for reporting whistleblowing.

Our first set of research expectations is that, all else being equal, managers when compared with non-managers should demonstrate significantly more trust in management, job satisfaction, organisational commitment and loyalty (for example, overall stronger organisational citizenship) and will exhibit greater support of whistleblowing. Further interest concerns how employee levels of job satisfaction relate to commitment to and support for whistleblowing. Does job satisfaction impact on levels of support for whistleblowing? Are such relationships magnified for managers? It could be expected that among dissatisfied employees, lower levels of support for whistleblowing would be observed, given that whistleblowing could itself gauge beliefs about procedural justice, fairness, organisational loyalty and commitment. In contrast, levels of support for whistleblowing as well as knowledge of the procedures for reporting it could be much greater among managers and employees generally who are satisfied with their work. In these circumstances, job satisfaction could link directly to trust, organisational citizenship and loyalty, which could foster a greater sense of awareness of the role of whistleblowing as well as the importance of effectively managing such events. It is therefore reasonable to expect that support for whistleblowing among managers and non-managers alike could be accentuated for employees with higher levels of job satisfaction.

Our second set of expectations is that managers will also demonstrate greater knowledge of the procedures triggered by the reporting of wrongdoing, including their own obligations in respect of it. Does job satisfaction impact on knowledge of procedures for reporting whistleblowing? Do managers have greater understanding of specific legal provisions in relation to whistleblowing? Our 
approach will explore whether managers differ from non-managers in this key aspect of whistleblowing management.

It is recognised that, all else being equal, managers as a group could be reasonably expected to have higher levels of trust and commitment to their organisations (especially in their own management - that is, themselves) as well as greater awareness of the importance of whistleblowing and the related procedures for handling internal disclosures. Part of the value of the current research is in attempting to gauge this empirically across a large sample of public sector employees in Australia. Absent any strong empirical base, beliefs and expectations about whether managers hold greater levels of organisational trust, job satisfaction and citizenship as well as support for whistleblowing when compared with non-managers are based simply on hunches and anecdotal information. Our aim is to examine and test such relationships (even ones that appear obvious) with hard data to provide more empirical evidence and therefore facilitate a broader, more in-depth body of knowledge in this area.

The first expectations are explored by examining whether managers differ from non-managers on a range of key organisational climate measures, drawn from the employee survey. Of the 7663 respondents to the survey, 1620 (21 per cent) identified as managers. Additionally, differences across employees with varying levels of job satisfaction are directly assessed. In this way, it can be explored whether there are consistent relationships linking job satisfaction to whistleblowing knowledge and attitudes. We also examine whether support for whistleblowing is a direct function of organisational role, such as being a manager. Finally, the direct predictive relationships between managerial status and support for whistleblowing are examined to assess whether managers have an increased probability of supporting whistleblowing net of various organisational dimensions including job satisfaction.

Measures used are similar to those employed in Chapter 3, including OCB (Graham 1989), trust in management (Robinson and Rousseau 1994), job satisfaction (Agho et al. 1992) and whistleblowing propensity (Keenan 2000, 2002; Tavakoli et al. 2003). ${ }^{4}$ The analysis proceeds in stages. First, mean-level comparisons between managers and non-managers on a range of organisational measures are presented. Statistical comparisons are employed using t-tests. Second, comparisons of measures of organisational characteristics for respondents differentiated on their levels of job satisfaction (for example, low, medium-low, medium-high, high) are presented using ANOVA procedures. These groups are constructed by creating quartiles across the distribution of the job-satisfaction variable. In the final stage of the analysis, the results are presented from an ordinary least squares (OLS) regression model to predict levels of support for whistleblowing net of other influences. 
The second set of expectations is explored using those items relating to knowledge of reporting procedures from the whistleblowing-propensity scale. We also examine whether knowledge of reporting procedures is a direct function of organisational role, such as being a manager. This analysis is, however, extended by examining descriptive statistics regarding the level of knowledge indicated by managers and non-managers about relevant legislation. Given the special role played by legislation in setting general standards for the management of whistleblowing, and in particular setting frameworks for managers' obligation as managers, this provides a window into perceived needs as well as current strengths.

\section{Managers, job satisfaction and support for whistleblowing}

The first series of comparisons involves directly comparing managers with non-managers on a series of organisationally relevant measures. The comparisons are reported in Table 7.1. The findings demonstrate a fairly consistent picture. The broad trend across the reported attitudinal variables suggests the manager sample has a more positive view of the organisation than non-managers. Managers, as a group, across the sample demonstrate significantly higher mean levels of trust in management, higher job satisfaction and higher levels of OCB. In particular, managers see themselves as more helpful to their fellow employees and as showing greater initiative than non-managers. The only OCB in which managers did not report higher levels than non-managers was the 'industry' factor, with managers and non-managers reporting the same levels. Furthermore, managers as a group demonstrated greater levels of support for whistleblowing, measured in terms of having a favourable personal attitude to whistleblowing. Perhaps not surprisingly, comparisons also show that managers as a group held significantly longer terms of employment with their current employer when compared with non-managers.

\section{Does job satisfaction relate to whistleblowing support?}

Table 7.2 reports the relationship between levels of job satisfaction and various organisationally relevant variables including whistleblowing support. Inspection of the results also reveals a consistent finding. Levels of employee job satisfaction appear directly related to salient organisational variables including trust in management, organisational citizenship and support for and knowledge of whistleblowing procedures. Employees with high levels of satisfaction, as indicated by the respondents in the upper quartiles of the scale distribution, score significantly higher than other respondents. 
Table 7.1 Comparing managers with non-managers for various organisational dimensions

\begin{tabular}{lccc}
\hline & $\begin{array}{c}\text { Managers } \\
(\mathbf{n}=\mathbf{1 6 1 2})\end{array}$ & $\begin{array}{c}\text { Non-managers } \\
(\mathbf{n}=\mathbf{5 ~ 9 1 2 )}\end{array}$ & t-value \\
\hline $\begin{array}{l}\text { Trust in management } \\
\text { Job satisfaction }\end{array}$ & 3.59 & 3.34 & $10.57^{*}$ \\
Organisational: & 3.61 & 3.43 & $8.62^{*}$ \\
Citizenship & & & \\
Helping & 3.90 & 3.74 & $14.28^{*}$ \\
Initiative & 4.02 & 3.94 & $5.89^{*}$ \\
Industry & 4.02 & 3.69 & $22.37^{*}$ \\
Loyalty & 3.84 & 3.84 & 0.35 \\
Whistleblowing propensity: & 3.72 & 3.49 & $11.96^{*}$ \\
Attitudes to whistleblowing & & & \\
Knowledge of procedures & 4.26 & 4.07 & $12.57^{*}$ \\
Length of time with organisation & 3.66 & 3.34 & $14.46^{*}$ \\
\hline
\end{tabular}

${ }^{*} \mathrm{p}<0.01$ two-tailed

Table 7.2 Relationships between job satisfaction and organisational characteristics

\begin{tabular}{lccccc}
\hline & $\begin{array}{c}\text { 1st quartile: } \\
\text { low }\end{array}$ & $\begin{array}{c}\text { 2nd quartile: } \\
\text { low-medium }\end{array}$ & $\begin{array}{c}\text { 3rd quartile: } \\
\text { medium-high }\end{array}$ & $\begin{array}{c}\text { 4th quartile: } \\
\text { high }\end{array}$ & $F$ value \\
\hline $\begin{array}{l}\text { Trust in management } \\
\text { Organisational: }\end{array}$ & 3.02 & 3.51 & 3.77 & 4.01 & $111.10^{*}$ \\
Citizenship & & & & & \\
Helping & 3.69 & 3.82 & 3.91 & 4.18 & $133.25^{*}$ \\
Initiative & 3.89 & 3.94 & 4.00 & 4.25 & $48.01^{*}$ \\
$\begin{array}{l}\text { Industry } \\
\text { Loyalty }\end{array}$ & 3.88 & 3.94 & 4.02 & 4.24 & $54.62^{*}$ \\
Whistleblowing propensity: & 3.70 & 3.77 & 3.80 & 4.12 & $46.97^{*}$ \\
Attitudes to whistleblowing & 3.28 & 3.63 & 3.83 & 4.11 & $122.41^{*}$ \\
Knowledge of procedures & 4.19 & 4.22 & 4.22 & 4.44 & $21.79^{*}$ \\
\hline
\end{tabular}

${ }^{*} \mathrm{p}<0.01$ two-tailed

The consistent pattern of results suggests that employee satisfaction could be an important ingredient for organisational harmony and performance. The comparisons suggest that satisfied employees provide additional benefits to organisations including trust, loyalty and, importantly for present purposes, support for whistleblowing. At this stage, however, we cannot rule out the possibility that additional factors influence job satisfaction as well as some of the organisational factors, including support for whistleblowing.

\section{Comparing support for whistleblowing across levels of job satisfaction for managers and non-managers}

The next phase of the results considers whether support for whistleblowing among managers and non-managers is in part conditional on levels of job satisfaction. Given the prior results linking managerial roles and job satisfaction levels with support for whistleblowing, it raises the possibility that being highly 
satisfied at work, as opposed to being a manager, facilitates support for whistleblowing. Results reported in Figure 7.1 bear directly on this issue.

Figures 7.1a-d Support for whistleblowing among managers and non-managers by varying levels of job satisfaction

Figure 7.1a. Support for Whistleblowing Among Managers and Non-Managers by Low Job Satisfaction (0-25 $5^{\text {th }}$ Percentile)

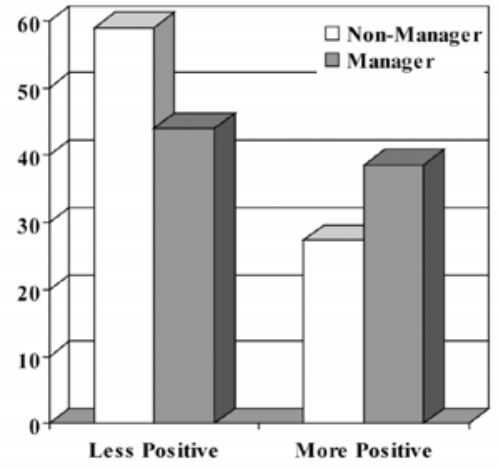

Figure 7.1c. Support For Whistleblowing Among Managers and Non-Managers by MedHigh Job Satisfaction (51-75 $5^{\text {th }}$ Percentile)

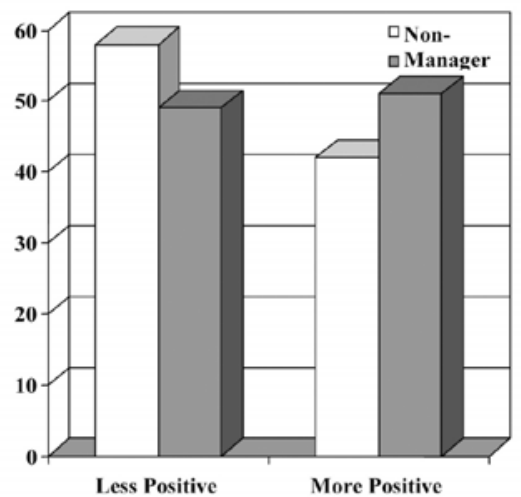

Figure 7.1b. Support for Whistleblowing Among Managers and Non-Managers by Low-Med Job Satisfaction (26-50 ${ }^{\text {th }}$ Percentile)



Figure 7.1d. Support For Whistleblowing Among Managers and Non-Managers by High Job Satisfaction (76-100 percentile)

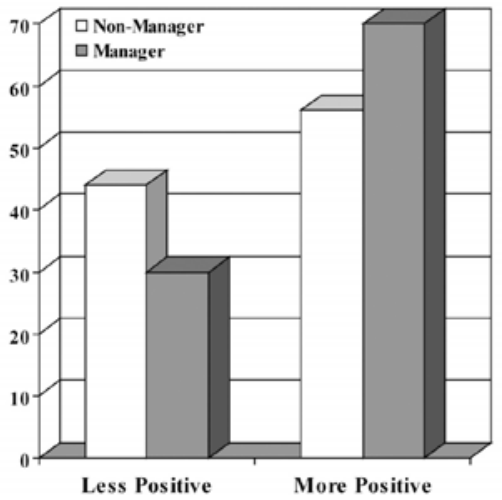

Results in Figures 7.1a-d show comparisons between managers and non-managers, across various levels of job satisfaction, on their specific levels of support for whistleblowing. For this comparison, the responses for the whistleblower support measure were differentiated at the fiftieth percentile to assess lesser or greater levels of support for whistleblowing. The picture emerging from the comparisons is clear: support for whistleblowing among managers and non-managers alike appears conditional on levels of job satisfaction. The findings reported in Figures 7.1a, 7.1b and 7.1c show that support for whistleblowing among managers is generally mixed between less and more support for 
respondents at the low or low-medium levels of job satisfaction. At higher levels of job satisfaction, however, a clear picture emerges, in which support for whistleblowing increases considerably. For example, at the seventy-sixth to the one-hundredth percentiles - indicating the highest level of job satisfaction - 70 per cent of managers supported whistleblowing compared with 30 per cent who were less positive. At lesser levels of job satisfaction, no marked differences were observed. In sum, support for whistleblowing among managers and non-managers appears accentuated at higher levels of job satisfaction and the relationship appears stronger for managers.

\section{Predictors of support for whistleblowing}

The next stage of the analysis examines a series of predictors of whistleblowing support. It is especially important to examine the predictive relationships to whistleblowing support in a multivariate context, given the range of possible influences that could affect such an outcome. Previous analysis suggested that managerial status was salient for whistleblower support, especially at higher levels of job satisfaction. In the next analysis, we explore whether these relationships remain while considering other actors, including demographic characteristics such as age and gender.

Because the outcome measure in this analysis-attitudes towards whistleblowing - comprises a continuous range of numbers, an OLS regression is appropriate. The results of an OLS regression allow researchers to gauge the amount of change in the outcome variable that results for every one-unit increase in the relevant predictor variable. The multiple-regression model results consider the precise relationships between individual independent variables, net of the effects of other influences. The results are reported in Table 7.3.

Table 7.3 Predictors of support for whistleblowing

\begin{tabular}{lccc}
\hline & $B$ & Std error & $t$ value \\
\hline Trust in management & 0.044 & 0.008 & $5.68^{*}$ \\
Job satisfaction & -0.044 & 0.009 & $4.82^{*}$ \\
Organisational citizenship & 0.413 & 0.016 & $25.12^{*}$ \\
Managerial status (1 = manager) & 0.107 & 0.015 & $6.98^{*}$ \\
Age & 0.002 & 0.001 & $3.12^{*}$ \\
Gender (1 = female) & 0.018 & 0.012 & 1.45 \\
Tenure with organisation & -0.0006 & 0.001 & 0.82 \\
Education & 0.031 & 0.006 & $5.16^{*}$ \\
Constant & 2.35 & 0.065 & $35.87^{*}$ \\
Adjusted $\mathrm{R}^{2}$ & 0.115 & & \\
$\mathrm{~N}$ & 7337 & & \\
\hline
\end{tabular}

${ }^{*} \mathrm{p}<0.01$ two-tailed 
Results from multiple-regression statistical models predicting support for whistleblowing reveal a range of statistically significant relationships. Table 7.3 reveals that having greater levels of trust in management, job satisfaction and organisational citizenship significantly increases the probability of support for whistleblowing. At the same time, older and more educated workers supported whistleblowing. Of significance was that being a manager increased the probability of supporting whistleblowing, net of other influences.

\section{Managers, job satisfaction and knowledge of whistleblowing procedures}

In assessing knowledge about whistleblowing policies in the workplace, a similar picture emerges. The relationships are reported and demonstrated in Figures $7.2 \mathrm{a}-\mathrm{d}$. The series of comparisons reveal that confidence in the ability to navigate whistleblowing policies is clearly stronger for managers who are more satisfied at work. For managers at low to low-medium levels of satisfaction, their professed familiarity with whistleblowing policies is equivocal. At higher levels of job satisfaction, reported knowledge of whistleblowing policies was much greater among managers - approaching 80 per cent. These results suggest there is a potential organisational benefit in having highly satisfied managers. Specifically, managers who are especially satisfied at work (on average) will not only have a more favourable personal attitude towards whistleblowing, they could be more able to put this attitude into practice through greater knowledge of relevant procedures.

\section{Predictors of knowledge of whistleblowing reporting procedures}

Findings reported in Table 7.4 reveal even more consistent predictors of knowledge of whistleblowing reporting procedures. The relationships reveal that job satisfaction, trust in management, organisational citizenship and being a manager are all predictive of knowledge of whistleblowing reporting procedures. Significant relationships were also observed for various demographic factors, with older workers, males, more educated staff and employees with lengthier tenure proving more knowledgeable about whistleblowing policies and practices. While these findings are not unexpected, it is important to assess empirically whether managers understand and support whistleblowing practices to a greater extent than non-managers, net of other salient organisational factors. 
Whistleblowing in the Australian Public Sector

Figures 7.2a-d Knowledge of whistleblowing procedures among managers and non-managers by varying levels of job satisfaction

Figure 7.2a. Knowledge of Whistleblowing Policies Among Managers and Non-Managers by Low Job Satisfaction (0-25 ${ }^{\text {th }}$ Percentile)

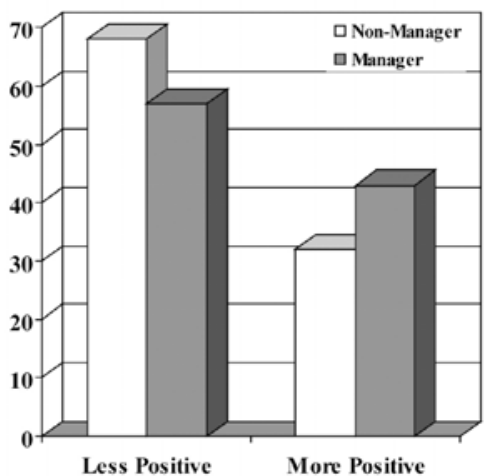

Figure 7.2c. Knowledge of Whistleblowing Policies Among Managers and Non-Managers by Med-High Job Satisfaction (51-75 ${ }^{\text {th }}$ Percentile)

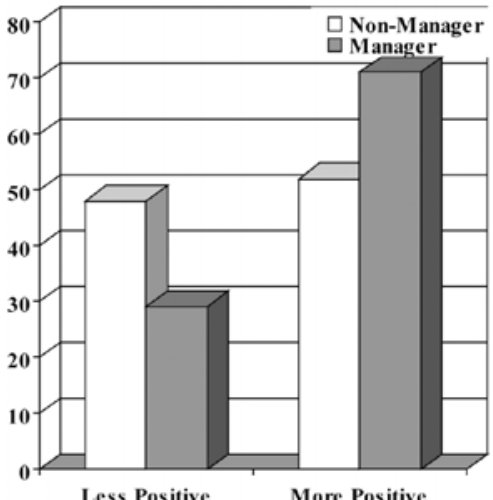

Less Positive
Figure 7.2b. Knowledge of Whistleblowing Policies Among Managers and Non-Managers by Med-

Low Job Satisfaction (26-50 $0^{\text {th }}$ Percentile)

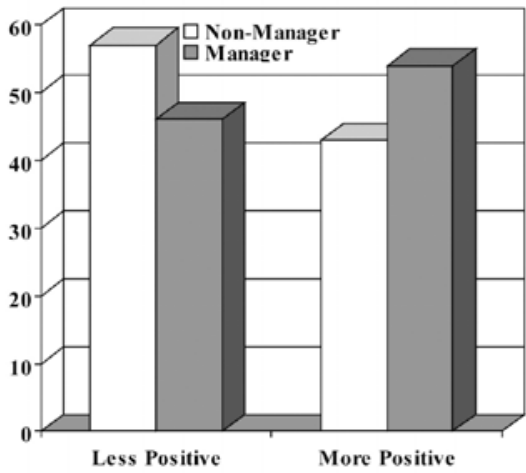

Figure 7.2d. Knowledge of Whistleblowing Policies Among Managers and Non-Managers by-High Job Satisfaction (76-100 ${ }^{\text {th }}$ Percentile)

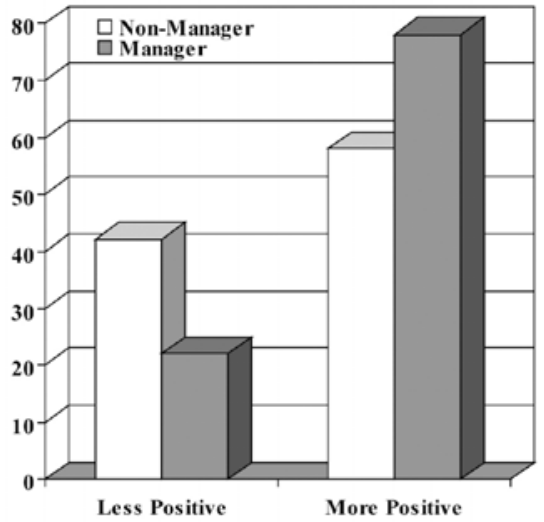


Table 7.4 Predictors of knowledge of whistleblower reporting procedures

\begin{tabular}{lccc}
\hline & $\boldsymbol{B}$ & Std error & $\boldsymbol{t}$ value \\
\hline Trust in management & 0.208 & 0.011 & $19.42^{*}$ \\
Job satisfaction & 0.056 & 0.013 & $4.41^{*}$ \\
Organisational citizenship & 0.376 & 0.023 & $16.53^{*}$ \\
Managerial status (1 = manager) & 0.145 & 0.021 & $6.87^{*}$ \\
Age & 0.004 & 0.001 & $4.23^{*}$ \\
Gender (1 = female) & -0.117 & 0.017 & $6.83^{*}$ \\
Tenure with organisation & 0.005 & 0.001 & $4.44^{*}$ \\
Education & -0.028 & 0.008 & $3.36^{*}$ \\
Constant & 0.996 & 0.091 & $10.99^{*}$ \\
Adjusted $\mathrm{R}^{2}$ & 0.17 & & \\
$\mathrm{~N}$ & 7338 & &
\end{tabular}

${ }^{*} \mathrm{p}<0.01$ one-tailed

\section{Managers and knowledge of whistleblowing legislation}

In the final analysis, it is important to relate the above findings back to the systems and procedures in the agencies under study and the proven duality in managers' roles. Given the marked tendency of employees to blow the whistle internally, shown in Chapter 4, the results above help explain why a lower than expected proportion of whistleblowers report bad treatment, shown in Chapter 5. Nevertheless, 18 per cent of all public interest whistleblowers did report that management treated them badly, with the proportion rising much higher in many agencies. A major goal of this research is to identify how that proportion of whistleblowers might be reduced.

While the above analysis indicates that job satisfaction of managers is an important variable, other factors influencing outcomes are likely to include the nature or extent of managers' knowledge of the relevant procedures and whether the content of the procedures themselves is appropriate. This last issue will be taken up in the following chapters. While managers might indicate a general confidence in and familiarity with whistleblowing procedures, the questions become how comprehensive is that knowledge and how well equipped are they to operationalise this generally favourable recognition of whistleblowing in their day-to-day roles? These questions are reinforced by the fact that the indicators of procedural knowledge reported above are the same as those used to gauge knowledge by all staff (that is, the scale-measured agreement with statements such as 'I have enough information about where to report wrongdoing, if such activities came to my attention' and 'I know what support my organisation provides for employees who report alleged wrongdoing'). The variables gauge respondents' confidence in the procedural aspects of blowing the whistle more than procedures relevant to managers' role as managers in this process.

To answer these questions, comparisons were also conducted to examine whether managers and non-managers answered questions relating to their knowledge of relevant legislation differently. Previous studies have recorded relatively low 
levels of awareness of relevant legislation among public employees (for example, Zipparo 1999a, 1999b), but the present study was not necessarily looking for either confirmation or change in that overall result - the need for most employees to know the specifics of legislation might be low, especially if the extent to which legislative principles are implemented by agency procedures is high. There is, however, reason to expect that managers should have a higher awareness of any relevant legislation. This is especially the case for the management of whistleblowing, where legislative reform has been a principal driver of new procedures and is directly intended to increase the overall responsiveness of management to whistleblowing. While the extent and quality of current legislation is further discussed in Chapters 10 and 11, the fact is that for most of the agencies studied, the management of whistleblowing has been the subject of relatively recent and topical legislative reform.

Table 7.5 displays the responses to the question asking whether respondents believe they are covered by legislation setting out their 'rights and responsibilities associated with reporting alleged wrongdoing' involving their organisation. The differences by jurisdiction highlight the many factors influencing awareness of legislation, including whether such legislation does in fact exist, whether the respondents' specific agency is covered and what efforts have been made to promote awareness of the legislation.

The responses confirm a high level of uncertainty about whether employees are covered by legislation, with 54 per cent of respondents indicating they did not know. As already noted, however, this is not necessarily surprising. The question is whether managers share this uncertainty in equal measure.

\section{Table 7.5 Awareness of legislation relating to whistleblowing}

\begin{tabular}{|c|c|c|c|c|c|}
\hline $\begin{array}{l}\text { Are your rights and } \\
\text { responsibilities covered by } \\
\text { legislation? }\end{array}$ & $\begin{array}{c}\text { Cth } \\
\text { (n = 2 307) }\end{array}$ & $\begin{array}{c}\text { NSW } \\
(n=2561)\end{array}$ & $\begin{array}{c}\text { Qld } \\
(n=1729)\end{array}$ & $\begin{array}{c}\text { WA } \\
(n=1007)\end{array}$ & $\begin{array}{c}\text { National } \\
\text { (n = } 7 \text { 604) }\end{array}$ \\
\hline Yes & $42.4 \%(935)$ & $\begin{array}{c}46.7 \%(1 \\
144)\end{array}$ & $47.6 \%(788)$ & $33.3 \%(320)$ & $\begin{array}{c}43.8 \%(3 \\
187)\end{array}$ \\
\hline No & $2.1 \%(46)$ & $1.7 \%(41)$ & $1.1 \%(18)$ & $2.2 \%(21)$ & $1.7 \%(126)$ \\
\hline Don't know & $\begin{array}{c}55.5 \%(1 \\
224)\end{array}$ & $\begin{array}{c}51.7 \%(1 \\
267)\end{array}$ & $51.3 \%(848)$ & $64.5 \%(620)$ & $\begin{array}{c}54.4 \% \text { (3 } \\
959)\end{array}$ \\
\hline Subtotal & $100 \%(2205)$ & $100 \%(2452)$ & $100 \%(1654)$ & $100 \%(961)$ & $100 \%$ (7 272) \\
\hline Missing & 102 & 109 & 75 & 46 & 332 \\
\hline
\end{tabular}

The results displayed in Table 7.6 reveal that managers do not share the same level of uncertainty as non-managers about whether they are covered by legislation. As the findings in Table 7.6 reveal, managers, as a group, are significantly less likely to indicate a lack of knowledge. Furthermore, and consistent with earlier results, managers also reported significantly greater confidence in the legislation they believed covered them, as shown in Table 7.7. 
Table 7.6 Manager and non-manager awareness of legislation

\begin{tabular}{l|cc}
\hline $\begin{array}{l}\text { Are your rights and responsibilities covered by } \\
\text { legislation? }\end{array}$ & $\begin{array}{c}\text { Managers } \\
\text { (n= 1620) }\end{array}$ & $\begin{array}{c}\text { Non-managers } \\
\text { (n = 5 966) }\end{array}$ \\
\hline Yes & $58.1 \%(901)$ & $40.0 \%(2287)$ \\
No & $1.5 \%(240)$ & $1.8 \%(104)$ \\
Don't know & $40.3 \%(625)$ & $58.2 \%(3324)$ \\
\hline Subtotal & $100 \%(1550)$ & $100 \%(5715)$ \\
Missing & 70 & 251 \\
\hline
\end{tabular}

Note: Significant at $\mathrm{p}=0.01$ using Chi-square test.

Table 7.7 Manager and non-manager confidence in legislation

\begin{tabular}{l|cc}
\hline $\mathbf{1}=$ strongly disagree & $\begin{array}{c}\text { Managers } \\
\text { (n = 1 012) }\end{array}$ & $\begin{array}{c}\text { Non-managers } \\
\text { (n = 2 735) }\end{array}$ \\
$\mathbf{5}=$ strongly agree & 3.71 & 3.58 \\
\hline $\begin{array}{l}\text { The existence of the legislation makes it easier } \\
\text { for me to consider reporting corruption. }\end{array}$ & 3.11 & $3.04 \mathrm{NS}$ \\
$\begin{array}{l}\text { I am confident that the legislation has the power } \\
\text { to protect me from any negative consequences } \\
\text { if I were to report corruption. }\end{array}$ & & 2.80 \\
$\begin{array}{l}\text { I believe that the legislation is ineffective. } \\
\text { The legislation is in need of major change to } \\
\text { improve employee reporting of wrongdoing }\end{array}$ & 2.69 & 2.99 \\
\hline
\end{tabular}

Note: All significant at $\mathrm{p}=0.01$ using Chi-square test (except where indicated by 'NS').

While these results are positive for managers and at a broad level continue to reinforce the results of the earlier analyses, there are nevertheless also signs that managers' knowledge of their specific obligations as managers in the whistleblowing process could be much stronger. In Table 7.6, the proportion of managers who did not know whether their rights and responsibilities were covered by legislation was still high (40 per cent). Apart from indicating a lack of awareness of specific obligations on them as managers, these results also show a substantial proportion of managers do not know whether their own staff are covered by relevant legislation.

There is also evidence that many managers themselves recognise their lack of knowledge when it comes to specific obligations. Among those respondents who did believe they were covered by legislation, there was still a significant desire for more information and training about the legislation. This is confirmed by Table 7.8, which shows that the perceived need for more information and training is particularly acute among managers, at whatever level of the organisation. Managers were significantly more likely than non-managers to indicate that they required greater information and training, notwithstanding that many managers were already confident that they were probably covered by the legislation. The higher perceived need for further information and training on the part of managers could in part reflect their role within the organisation, as well as their higher levels of organisational investment as indicated by their greater levels of citizenship (that is, loyalty, helping, and so on), trust in management and job satisfaction, which were demonstrated in earlier analysis reported in Table 7.1. It is, however, also probably an indicator that 
notwithstanding the generally positive attitude towards whistleblowing described earlier, the impacts of specific policies and procedures on the working lives of managers are not strong.

\section{Table 7.8 Need for more legislative information and training by managerial status}

\begin{tabular}{l|ccc}
\hline $\begin{array}{l}\text { I require more information and training about the } \\
\text { legislation. }\end{array}$ & $\begin{array}{c}\text { Managers } \\
(\mathbf{n}=\mathbf{1 0 3 4 )}\end{array}$ & $\begin{array}{c}\text { Non-managers } \\
\text { (n = 2 836) }\end{array}$ & $\begin{array}{c}\text { Total } \\
\text { (n = 3 900) }\end{array}$ \\
\hline $1=$ strongly disagree & $3.39^{*}$ & $3.26^{*}$ & 3.36 \\
$5=$ strongly agree & $(\mathrm{SD}=0.96)$ & $(\mathrm{SD}=0.93)$ & \\
\hline
\end{tabular}

* significant at $\mathrm{p}=0.01$ (two-tailed test)

\section{Discussion and conclusions}

This chapter examined the unique role of managers in relation to their support for whistleblowing as well as whether that support was conditional on their levels of job satisfaction. The results reveal a relatively consistent set of findings in relation to comparisons between managers and non-managers. Managers tend to have a much greater stake in their workplaces. They reveal higher levels of organisational affiliation in terms of organisational citizenship, trust in management and job satisfaction. At the same time, they appear to have a stronger recognition of the value of whistleblowing in the workplace.

An additional part of the analysis involved assessing independently whether job satisfaction was related to whistleblower support. The results show that respondents with the highest level of job satisfaction tend to also have the highest degree of support for whistleblowing, as well as the highest scores for other organisational variables. Given the salience of job satisfaction, comparisons were conducted to assess whether managerial support for whistleblowing was a function of levels of job satisfaction. The results reveal that job satisfaction was a salient facilitating factor of support for whistleblowing, as well as reported knowledge of reporting procedures. The findings therefore illustrate how experiences at work, in terms of whether one is satisfied or not, can lead to various tangible benefits across organisations. One of the hidden benefits for satisfied employees, regardless of their managerial status, is that they demonstrate much greater awareness of and competency towards whistleblowing.

This observation was largely reinforced in the multivariate analyses that revealed that being a manager increased the probability of support for whistleblowing net of various demographic and organisational influences. In short, over and above the role of organisational climate influences, it is clear that managers have a unique role to play in encouraging whistleblowing, even if this role is also often complex.

These results illuminate a suite of implications for managing whistleblowing in public sector organisations. The findings illustrate that managers are very well 
placed to materially affect their work environments. As mentioned at the beginning of this chapter, managers are crucial for providing a professional and productive work setting. Unfortunately, however, there are numerous examples whereby managerial competence is stretched and workplace experiences begin to unravel. In such settings, employee morale and concerns about fair work and decision making might no longer take priority (Byrne 2005). The results suggest that a concerted effort is needed if the potential contribution of good management cultures and styles to the productive management of whistleblowing is to be maximised.

Underscoring the potential for maximising the generally positive culture of management in the agencies studied is the evidence in the final part of the chapter that managers are far less certain about rights and obligations relevant to their own role in respect of real whistleblowing incidents. There are strong signs that managers themselves recognise the need to close the gaps between broad principle and practical realities. How this might be done becomes a question of agency systems and procedures, building on the general support for whistleblowing that has been found among individual managers. The environment exists for the development of better systems and procedures. This fact reinforces the imperatives that can now be more clearly identified for doing so, based on the current standard of systems and procedures described in subsequent chapters.

The current research is not without limitations. In addition to some of the methodological constraints outlined in Chapter 1 , the findings presented illustrate the need to conduct further, more fine-grained analyses. The findings suggest that many of the relationships between managers and whistleblower support and commitment are complex and various organisational context variables (for example, citizenship, loyalty, and so on) need to be further explored to assess the interactive or multiplicative influences. Additionally, the specific attributes of managers need to be further considered. Managers are clearly not a 'one-size-fits-all' category. Further analysis will need to explore a range of competencies as well as the possible relationship to gender and age to more fully consider the full range of influences that affect managers in their responses to and handling of whistleblowing. At the same time, a host of organisational context variables needs consideration. For example, there is reason to believe that organisational size can be a salient influence on job satisfaction and whistleblower support. Further analysis is needed to explore these issues in greater detail in a concerted attempt to understand the unique role of managers in handling whistleblowing in public sector organisations.

In summary, the findings from this research point to more effective strategies for promoting the importance of whistleblowing as well as the knowledge required to advance whistleblowing management practice. Strategies to promote an effective organisational climate appear salient to the extent that they facilitate 
job satisfaction among employees. Uncovering the key ingredients for facilitating job satisfaction for managers and non-managers alike provides the added benefits of there being more direct impact on the overall organisational health across public sector agencies. These results strengthen the evidence that whistleblowing is often recognised as necessary and even healthy in organisations and confirms the potential for building stronger systems for ensuring that the incidence of unfair treatment of whistleblowers is minimised. Perhaps most importantly, these results suggest that by investing in the job satisfaction of managers, as well as by promoting greater awareness among managers of their whistleblowing reporting obligations and procedures, organisations can do a great deal to reduce the risks of some of the outcomes described in earlier chapters, and increase the prospects of the whistleblowing process being handled well.

\section{ENDNOTES}

1 The authors thank Dr Peter Cassematis for research support on aspects of this chapter.

${ }^{2}$ We accept that managers operate across varying levels within organisations and that junior as opposed to more senior managers can shape their organisational settings in relation to whistleblowing (and other issues) in varying ways. It is the intention of the research team to further explore whether and to what extent support for whistleblowing as well as other organisational factors varies across levels of managers.

3 Of course, if individual managers are the targets of a whistleblowing event (that is, the perceived wrongdoers), their personal support for that act of whistleblowing will likely be low. This issue can be explored in further research as part of this larger project.

4 The measure for OCB (Graham 1989) comprises the sub-components of helping (five items; alpha = 0.74 ), initiative (five items; alpha $=0.80$ ), industry (four items; alpha $=0.67$ ) and loyalty (five items; alpha $=0.83$ ). Trust in management (Robinson and Rousseau 1994) is assessed by a seven-item scale that gauges the extent to which respondents believe that managers will treat employees fairly (alpha $=$ 0.90). Job satisfaction (Agho et al. 1992) is gauged with a six-item scale to assess employee job satisfaction and enjoyment with their employment role and working conditions (alpha $=0.86$ ). Whistleblowing propensity is assessed using a scale developed by Keenan (2000), which has two discrete components: attitudes towards whistleblowing (five items; alpha $=0.84$ ) and knowledge of reporting procedures (five items; alpha $=0.84$ ). 